\title{
As Sociabilidades Juvenis e suas Relações na Diversidade do Espaço Escolar
}

\author{
I Las sociabilidades Juveniles y sus Relaciones en la Diversidad del \\ Espacio Escolar
}

\section{The Sociabilities Juveniles and their relations in the School Space}

\author{
Ma. Maristela Piber Maciel ${ }^{1}$
}

\begin{abstract}
Resumo
As práticas escolares são mediadas por relações sociais, sociabilidades, desigualdades e diferenças étnicas, de gênero e de valores. A escolarização dos jovens de camadas populares é frequentemente associada ao fracasso escolar, do aluno desinteressado e indisciplinado. Estas classificações acabam por transferir aos alunos a responsabilidade pelo fracasso. Quais os significados que esses alunos atribuem à escola? Qual é a visão dos/as alunos/as sobre a escola? Ao responder essas perguntas, buscamos identificar práticas cotidianas de sociabilidades de jovens de classes populares no interior da escola e suas percepções deste local. A pesquisa orientou-se por essas perguntas tendo como objetivo geral analisar, através das experiências de jovens no cotidiano de convivências informais, os significados da escola e as sociabilidades neste espaço. A metodologia qualitativa adotada nesta pesquisa é etnográfica composta por um trabalho de campo com a utilização de imagens. Foram identificados grupos que se colocam durante o recreio em delimitações espaciais, corporais com interesses e estilos diversos, estabelecidas a partir de vários marcadores sociais das diferenças - classe, gênero, etnia, geração etc. As análises iniciais das práticas de sociabilidade mostram que a escola transforma-se para estes jovens em um espaço de relacionamento, lazer e de convívio.
\end{abstract}

Palavras-Chave: Culturas Juvenis; Diversidade Cultural; Igualdades e Diferenças; Relações Escolares.

\section{Resumen}

Las prácticas escolares son mediadas por relaciones sociales, sociabilidades, desigualdades y diferencias étnicas, de género y de valores. La escolarización de los jóvenes de los estamentos populares es frecuentemente asociada al fracaso escolar, del alumno sin interés e indisciplinado. Estas clasificaciones terminan por pasar a los alumnos la responsabilidad por el fracaso. ¿Cuáles son los significados que esos alumnos atribuyen a la escuela? ¿Cuál es la mirada de los/las alumnos/as sobre la escuela? Al contestar esas preguntas, buscamos identificar prácticas cotidianas de sociabilidades de jóvenes de clases populares en el interior de la escuela y sus percepciones de este local. Esta investigación tuvo como reto esas preguntas y como objetivo general analisar a travéz de las experiencias de jóvenes en el cotidiano de convivencias informales, los significados de la escuela y las sociabilidades en este espacio. La metodologia cualitativa adoptada en esta investigación es etnográfica compuesta por un trabajo de campo con la utilización de imágenes. Fueron identificados grupos que se ubican durante el recreo en delimitaciones espaciales, corporales con intereses y estilos diversos, establecidas apartir de varios marcadores sociales de las diferencias - clases, género, etnicidad, generación etc. Las análisis iniciales de las prácticas de sociabilidad muestran que la escuela se transforma para éstos jovenes en un espacio de relacionamento, ocio y de convivio.

Palabras clave: Culturas Juveniles; Diversidad Cultural; Igualdades y diferencias; Relaciones Escolares.

\section{Abstract}

\footnotetext{
${ }^{1}$ Mestra em Ciências Sociais; Universidade do Vale do Rio dos Sinos - Unisinos; Porto Alegre, Rio Grande do Sul, Brasil; marismaciel@ibest.com.br.
} 

e-ISSN 2016/Atual: 2525-7870 | e-ISSN 2015/2016: 2447-018X

School practices are mediated by social relations, sociability, inequality and ethnic differences, gender and values. The education of the youth of popular classes is often associated with school failure, disinterested and undisciplined student. These ratings end up transferring students the responsibility for the failure. What are the meanings that these students attribute to school? What is the vision of / the students / the School? In answering these questions, we seek to identify daily practices of sociability popular classes of young people within the school and their perceptions of this site. The research was guided by these questions with the general objective to analyze, through the experiences of young people in the informal cohabitation everyday, school meanings and sociability in this space. The qualitative methodology used in this research is composed of ethnographic fieldwork with the use of images. groups were identified that arise during recess in spatial, bodily boundaries with diverse interests and styles, established from various social markers of differences - class, gender, ethnicity, generation etc. Initial analyzes of sociability practices show that the school becomes for these young people in a relationship of space, leisure and recreation.

Keywords: Youth Cultures; Cultural Diversity; Equalities and differences; School Relations.

\section{Introdução}

$\mathrm{Na}$ escola as práticas educativas são mediadas por relações socioculturais, processos de transmissão de saberes, sociabilidades, temáticas como desigualdades sociais, diferenças étnicas, de gênero e valores éticos- morais. A escolarização de crianças e adolescentes de camadas populares é frequentemente associada à ideia de fracasso escolar, e este pode ser percepcionado como responsabilidade do aluno desinteressado, do aluno indisciplinado e, por extensão, da família desestruturada (DAL'IGNA, 2011; FONSECA, 1994; GROSSI, 2004) Estas classificações acabam por transferir aos alunos a responsabilidade pelo fracasso, como indica a expressão desinteresse em aprender.

Esta pesquisa propõe um deslocamento da escola em si e da prática docente para os/as jovens, com o interesse em aprofundar a relação entre os/as jovens e o espaço escolar, especificamente sobre a visão dos/das jovens sobre a escola e sobre as sociabilidades presentes neste espaço.

Sem a intenção de propor ou problematizar lógicas distintas para professores e alunos/as, a possibilidade de deslocar o olhar de docente para focar sobre os/as jovens permitindo analisar estas classificações presentes em instituições de ensino desde a perspectiva do significado do espaço escolar para os/as adolescentes.

Além das diferenças geracionais entre professores e alunos/as, também as desigualdades de oferta do ensino segundo a classe social é um elemento a ser levado em consideração em estudos envolvendo adolescentes de camadas populares, como ilustra o documentário Pro dia nascer feliz, do diretor João Jardim (2006). Ele apresenta realidades distintas em três estados brasileiros e deixa ver através dos depoimentos de pais, alunos e professores, bem como através da comparação entre as diferentes estruturas físicas de prédios escolares nesses estados, o formato das desigualdades de condições na oferta do ensino público no país. 

e-ISSN 2016/Atual: 2525-7870 | e-ISSN 2015/2016: 2447-018X

Ficam evidentes aspectos relativos às relações de poder e à dicotomia entre as linguagens e formas de pensar dos alunos/as e professores/as, uns colocando a culpa nos outros, expondo os problemas e conflitos nas instituições públicas de ensino fundamental e médio. Nessa trilha, o documentário apresenta em imagens o que Tânia Dauster (2012) tem analisado em seus trabalhos sobre as interfaces entre antropologia e educação:

(...) a escola, por inserir-se na sociedade mais ampla, é um espaço social de reprodução e produção de ideologias e de relações de dominação marcadas por conflitos, resistências e razões que são expressão das relações entre homens. Não há, portanto, como falar de educação sem levar em conta o campo de tensão social e político que envolve a vida em sociedade (...). (DAUSER, 2012, p. 22).

Neste sentido, este trabalho pesquisa os significados que os jovens atribuem à escola $\mathrm{e}$ as concepções que eles tem acerca dela. O universo empírico foi delimitado em uma escola pública municipal, localizada na região Norte de Porto Alegre -RS, com alunos do terceiro ciclo do ensino fundamental final.

As questões de interesse na pesquisa são: qual a visão dos/as jovens sobre a escola? Qual a visão que os/as jovens têm sobre a educação escolar? Como se dão as relações de sociabilidade, no espaço escolar entre jovens de camadas populares? Serão estes os interrogantes que ajudarão a delinear o significado da escola na vida dos jovens investigados.

A partir do problema apresentado proponho como objetivo geral da pesquisa analisar, através das experiências dos jovens de classes populares do/no cotidiano escolar, os significados da escola e as sociabilidades no espaço escolar.

Para o desenvolvimento da pesquisa e para conduzir as análises dos dados coletados em campo foi utilizado o método etnográfico.

\section{Referencial Teórico}

Considerando o tema central desta pesquisa a relação entre jovens e o espaço escolar, com o objetivo de analisar a perspectiva dos/as alunos/as sobre a escola e as sociabilidades neste espaço, o referencial teórico da pesquisa foi construído a partir das seguintes considerações, uma historicização da instituição escolar em simultâneo às classificações etárias; um estudo sobre as categorias jovens /adolescentes, pois possuem significados diferentes, mas muitas vezes são utilizados até como sinônimo. Também foi realizada uma revisão da literatura sobre a relação entre jovens/adolescentes e a instituição escolar e foi feita uma abordagem da antropologia sobre educação e etnografias do espaço escolar com algumas 
contribuições sobre a cultura como construção de significados que focalizam as práticas sociais do ponto de vista dos atores.

\subsection{A instituição escola e as categorias em perspectiva histórica e antropológica}

A instituição escolar, nascida durante a transição da Idade Média e a Idade Moderna, trouxe em sua ideologia de fundação os valores daquela sociedade, que buscava atender e preparar a população infantil para idade adulta. Conforme afirma a antropóloga Ana Luiza Rocha a escola atualmente continua configurada com estes valores de classificação e separação das pessoas:

Portanto, o modo pelo qual na escola por ciclos a vida é periodizada e o tipo de desenvolvimento da inteligência que está associado aos grupos etários da vida, não se configuram como um processo de respeito ao ritmo natural do aluno, mas antes são formas de classificação e separação dos seres humanos empregados pelos profissionais da Educação e, em particular, para o caso de escolas públicas que atendem crianças e adolescentes das periferias de nossas grandes cidades (ROCHA, 2004, p. 114).

Para fins deste quadro analítico, estas considerações importam na medida em que há uma delimitação etária em sintonia com o desenvolvimento da instituição escola e suas atribuições sociais. Neste estudo, utilizaremos como delimitação empírica alunos/as do terceiro ciclo de formação, que, segundo orientações do MEC, compreende a faixa etária dos 12 aos 14 anos e 11 meses $^{2}$. Entretanto, seguiremos o estudo de Tosta e Carvalho (2015), que partiram de uma delimitação inicial sobre adolescência, sendo esta posteriormente adequada às classificações advindas do próprio campo da pesquisa.

Uma questão teórica metodológica importante do trabalho foi o fato de não ocorrer uma fixação rígida nas idades do estudo, mas uma escuta dos diferentes grupos de pertença nas relações entre grupos e pares e como estes se reconheciam. As autoras foram guiadas pelas seguintes questões: como se identificam os adolescentes nos múltiplos pedaço da instituição escolar e os diferentes grupos e localizações destes na escola (pátio, refeitório, banheiro)? Como se identificam geográfica, espacial e corporalmente?

As autoras ampliam a classificação da categoria adolescente, pois existe uma confusão sobre os termos juventude e adolescência, e a faixa etária que abrange. Este estudo parte de

\footnotetext{
${ }^{2}$ PMPA/SMED/Cadernos Pedagógicos nº 9 /Abril de 1999.
} 
diferentes autores a fim de conceituar esta categoria e corroboram com os estudos de Fonseca (1994) que aborda não como um conceito universal.

\subsection{Categorias jovens/adolescentes}

Sobre os conceitos sobre adolescência e juventude, são categorias produzidas Este exemplo do filme revela a existência de diferentes discursos sobre jovens e as suas relações com a escola. Estes diferentes discursos constituem formas de viver a realidade, dependendo do lado e da posição onde se encontra, demonstrando que as categorias como adolescentes, jovens e juventudes não são homogêneas. Tais discursos indicam, entretanto, que a juventude tem sido analisada e problematizada a partir de vários pontos de vista e por diversos campos disciplinares como psicologia, biologia, sociologia, educação. Portanto, a juventude aparece como um construto que se constituiu ao longo da história da humanidade, sendo representada e vivida de diferentes modos, nesta pesquisa optou-se pela noção de juventudes compreendida como condição histórico cultural como uma representação não dada e não fixa, como categorial socialmente construída (ARIÈS, 1981, MEAD, 1975; ABRAMO, 2005 CALLIGARIS, 2000) que se constituem combinadas com os diversos marcadores sociais e culturais como localidade, regionalidade, classe, gênero, geração e raça.

\subsection{Abordagens sobre a relação entre adolescentes /jovens e a instituição escolar}

A educação e a psicologia têm buscado entender as dinâmicas e os conflitos que ocorrem entre os atores sociais na escola, que está inserida nesta sociedade complexa com grande heterogeneidade social e cultural. Conforme Claudia Fonseca (1994), para entender estes conflitos será necessário situar as dinâmicas familiares particulares aos grupos populares, seus entendimentos sobre infância, adolescência e socialização coerentes com a visão do mundo destes sujeitos em questão. Segundo a mesma autora, a antropologia fornece instrumentos para colocar em perspectiva práticas e valores destes outros e práticas e valores nossos.

Na busca de entender o lugar da escola no sistema de valores dos grupos populares e suas redes de sociabilidades, a antropóloga Claudia Fonseca (1994) realizou uma pesquisa etnográfica com a seguinte hipótese que apesar do prestigio atribuído ao ensino nem na realidade nem no sonho a instituição escolar muda grande coisa na vida dos moradores do bairro e as famílias, que investem em outras formas de socialização. Fonseca (1994) seguiu seu estudo evitando questionários fechados, conversando com pessoas fora do âmbito escolar, entrando nos circuitos cotidianos de sociabilidades. 
O que Fonseca (1994) constatou foi que a escola é valorizada, mas é inacessível para as classes populares "ter estudo - um status de difícil acesso":

Já que a maioria dos pais possui pouca experiência escolar, não se dá conta dos problemas de infraestrutura do sistema escolar procuram outras explicações para o fracasso de seus filhos. Alguns formulam hipóteses apoiadas por especialistas de neurologia ou pedagogia com hipótese de que seus filhos "não tem cabeça para o estudo" ou problemas idiossincráticos do colégio que frequentam "as professoras não dão valor para as crianças, não estimulam ninguém”. (FONSECA, 1994, p. 145)

Durante o estudo foi constatada uma confusão entre o termo adolescente e delinquente. Segundo Fonseca (1994), a ausência, neste grupo, de um conceito específico de adolescência coloca em relevo uma diferença significativa entre os membros dos grupos populares e o das camadas médias contemporâneas.

$\mathrm{O}$ argumento mais relevante deste estudo é que nas classes populares um erro durante a adolescência não é transitório ou recuperável, para eles é um passo para a vida adulta não desejada: namorar, morar com alguém, fugir de casa, engravidar, ser deixado pelo companheiro, transformar-se em marginal, roubar, traficar, fumar maconha, morte ou cadeia.

A constatação de Fonseca (1994) é que a escola não ocupa um lugar central nas preocupações dos pesquisados. De uma maneira comum as rotinas cotidianas são orientadas por outras prioridades e a autora traz em seu texto alguns questionamentos ainda pertinentes para os dias atuais:

Por que estas pessoas iam reconhecer os benefícios evidentes do ensino escolar? Porque submeter-se a esta lógica? Adaptar-se ao seu relógio? A sua escala de valores? Ainda se trata de um esforço de um indivíduo... mas pelo contrário, o êxito escolar depende de uma reorientação dos hábitos da família inteira. (FONSECA, 1994, p.148)

Para uma análise aprofundada, estas considerações importam na medida em que há um questionamento sobre as rotinas cotidianas e as prioridades com relação às escolas. De modo a entender o lugar da escola no sistema de valores dos grupos populares do Brasil urbano, Fonseca (1994) salienta que se faz importante pensar como se dá o modo de socialização, questões de éticas e valores dos diversos grupos no interior da escola como enfrentar estes problemas como: situações de violência, indisciplina e bullying. 


\subsection{Sobre a abordagem antropológica da educação}

Neusa Maria Mendes Gusmão (1997) é uma das percussoras desta interface entre antropologia e educação no Brasil, ela trata sobre as diferenças entre os dois campos -Antropologia e Educação: o primeiro possui o status de ciência e o segundo situa-se na esfera da prática, a autora busca ressaltar os aspectos em comum a fim de propor um diálogo entre os campos. Primeiro ela esclarece alguns conceitos básicos para a antropologia e após traz um histórico da antropologia dialogando com a educação.

Segundo Gusmão (1997) a educação pode ser percebida como um modo de ajustamento baseado na organização social e no horizonte cultural compartilhado por um mesmo grupo. Ela exemplifica que todas as sociedades possuem modos para incentivar e corrigir seus integrantes passando seus valores e normas. Entende cultura como um mecanismo necessário para o ser humano viver, diferenciando as esferas da natureza e da cultura, lugar de onde se constrói um saber que envolve os modos de socialização e aprendizagem. O relativismo no ponto de vista da autora é a superação do etnocentrismo é o conhecimento do diverso para compreendê-lo em relação, relativizar "o próprio pensamento para construir um conhecimento que é o outro" (GUSMÃO, 1997, p.4).

Concluindo seu trabalho, a autora pontua que a antropologia interpretativa é um desafio, o questionamento das práticas científicas e das práticas educativas a partir do trabalho de campo e do fazer etnográfico.

Este trabalho vem contribuir para aprofundamentos deste estudo viabilizando uma reflexão sobre o conjunto das diferenças, viabilizando abrir um espaço paro o debate, a reflexão e a intervenção a fim de acolher um contexto cultural das aprendizagens das diferenças culturais (racial, étnica, gênero, seus efeitos, sucessos e insucessos do sistema escolar) como uma preocupação dos antropólogos com as diferentes práticas educativas.

No trabalho de Tatiana Cipiniuk (2014) é possível pensar a instituição escolar com o olhar antropológico, como uma possibilidade de campo, um lugar para análise, suas possibilidades e dificuldades. A autora narra os momentos de deslocamento empírico que passou (CIPINIUK, 2014) durante sua pesquisa etnográfica, ela justifica que no caso da escola, que possui uma dinâmica pautada sobre princípios pragmáticos de uniformidade e padronização nem sempre se adapta aos desafios instaurados pelo trabalho de campo etnográfico:

Portanto, desnaturalizar o contexto escolar, cujo universo é tão compartilhado pelo pesquisado quanto para o pesquisador, implica uma oportunidade de análise irrefutável para marcar a forma como as teorias e métodos devem ser problematizados (CIPINIUK, 2014, p.87). 
Em seu trabalho esta autora questiona este contexto escolar, as possibilidades e dificuldades de se realizar uma pesquisa de campo em contextos escolares. Cipiniuk (2014) pontua os cuidados que o pesquisador precisa ter quando se insere no campo, que está inserção é um investimento cuidadoso de alto risco tanto para o desenvolvimento com êxito como para um possível insucesso. Isso pode ser um complicador quando o ambiente a ser pesquisado possui caráter normativo, de produção e reprodução social, rotinas rígidas, tempos padronizadas e socializações disciplinares, neste caso a escola pública brasileira.

Neste sentido, este trabalho busca focalizar as percepções dos jovens sobre a escola. $\mathrm{O}$ universo empírico foi delimitado em uma escola pública municipal, localizada na região Norte de Porto Alegre - RS, com alunos do terceiro ciclo do ensino fundamental final.

\section{Objetivos}

Para dar conta do problema apresentado especificamos a seguir os objetivos e metodologia que estão conduzindo a análise. Este trabalho teve por objetivo geral analisar, através das experiências dos jovens de classes populares do/no cotidiano escolar, os significados da escola e as sociabilidades no espaço escolar. Como objetivos específicos: a)Identificar e analisar as sociabilidades dos jovens no espaço escolar; b) Analisar os significados das concepções dos/as alunos/as sobre a escola e qual o lugar que ela ocupa nas suas vidas e c)Analisar as experiências dos jovens no e com o contexto escolar, a partir de suas narrativas.

\section{Metodologia}

A pesquisa foi desenvolvida a partir de metodologia qualitativa, considerada como o mais apropriado para interpretar e entender as trajetórias e as relações de um determinado grupo (GOLDENBERG, 2009). O trabalho foi desenvolvido a partir do método etnográfico de pesquisa considerando as orientações de Fonseca (1999), com realização de um trabalho de campo com observação participante e realização de entrevistas, organizadas e analisadas a luz da teoria interpretativa da cultura (GEERTZ, 1989).

A pesquisa foi realizada na escola onde atuo profissionalmente, de forma que meus interlocutores em campo serão meus ex-alunos. A escolha do campo foi decorrência da facilidade no acesso à escola e alunos/as. Esta proximidade com o universo da pesquisa, enquanto professora, foi nuançada pela diferença etária entre pesquisadora e jovens.

O universo empírico deste estudo foi uma escola pública municipal de ensino fundamental situada numa localidade periférica, na zona norte de Porto Alegre- RS. A escola 

e-ISSN 2016/Atual: 2525-7870 | e-ISSN 2015/2016: 2447-018X

foi fundada em fevereiro de 2001. A área do loteamento foi adquirida e escriturada pelo $\mathrm{DEMHAB}^{3}$ em julho de 1992. Antes do loteamento era uma chácara com produção de alimentos e animais O reassentamento das primeiras famílias iniciou-se no ano de 1992 e visou instalar famílias que vinham de áreas de risco, de despejos e deslocamentos. Este histórico é importante para contextualizar como um espaço de periferia

Seu espaço físico é composto de dois prédios de alvenaria, com dois pavimentos, um com salas de aula, outro com salas de aula e salas de informática, biblioteca, sala de robótica além de área administrativa, um anexo com banheiros e um prédio com cozinha, refeitório e uma cancha poli esportiva.

Atualmente a escola atende o ensino fundamental com alunos entre os 5 e os 17 anos, nos turnos da manhã e tarde, possuem 55 professores e 830 alunos matriculados. . Os alunos de terceiro ciclo que compõem o público da pesquisa frequentam sete turmas seis pela manhã e uma na parte da tarde num total de 200 alunos. Destes um grupo de 15 alunos participaram ativamente da pesquisa.

\section{Constatações preliminares}

Apresentamos aqui algumas situações observadas de interações livres entre os pares que ocorrem nesses momentos não formais de ensino, propondo uma análise deste cotidiano das convivências informais, a fim de caracterizar os significados da escola para os jovens e as sociabilidades que ocorrem neste espaço. Estas análises permitem descrever como os jovens ocupam o espaço escolar e quais são as configurações culturais ou de gênero que ocorrem durante estes agrupamentos.

\footnotetext{
${ }^{3}$ Departamento Municipal de Habitação (DEMAHAB) é a autarquia responsável pela gestão da Política Habitacional de Interesse Social do Município de Porto Alegre.
} 
RELACult - Revista Latino-Americana de Estudos em Cultura e Sociedade

Revista Latinoamericana de Estudios en Cultura y Sociedad | Latin American Journal of Studies in Culture and Society V. 02, Ed. Especial, dezembro, 2016, p. 520-531| periodicos.claec.org e-ISSN 2016/Atual: 2525-7870 | e-ISSN 2015/2016: 2447-018X

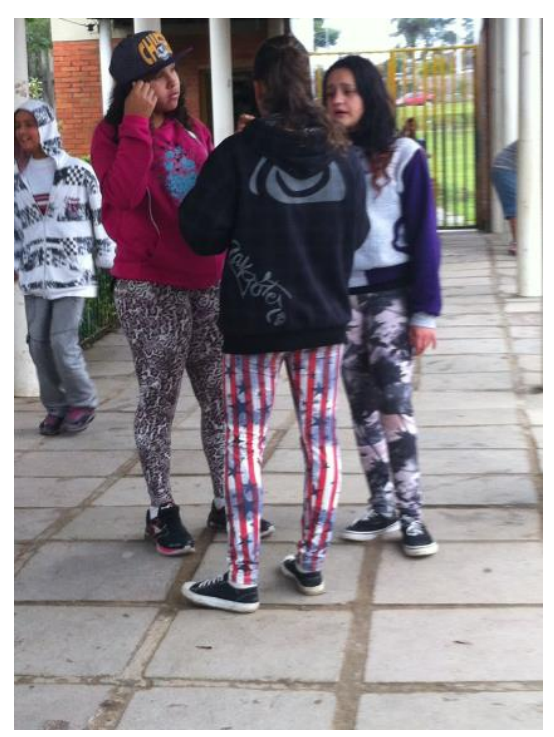

Fotografia 1: Grupo de meninas conversando no recreio Foto: Maristela Maciel, Agosto, 2015.

Já foi possível identificar alguns grupos no recreio com configurações distintas de atividades e gênero, que gostam do futebol, música ou conversas. Estes grupos se colocam durante o recreio em delimitações geográficas, espaciais e corporais distintas. A partir de alguns depoimentos constatamos que a escola transforma-se em um espaço de lazer e convívio para estes jovens e suas manifestações culturais.

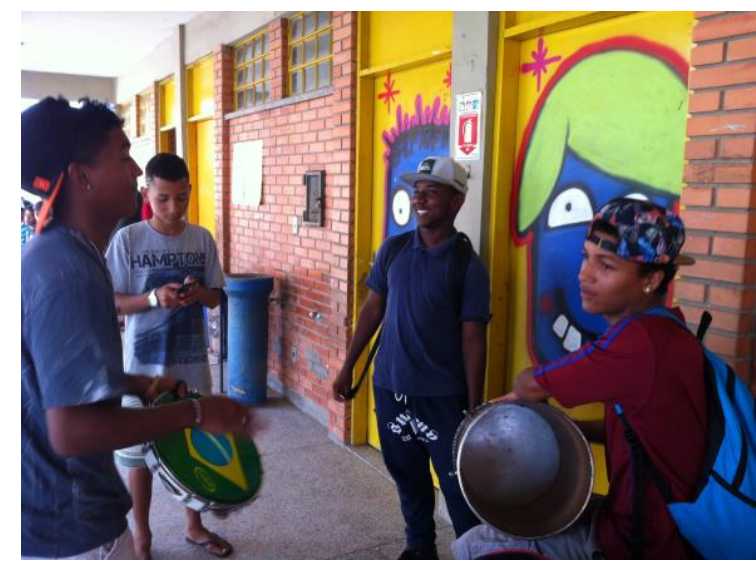

Fotografia 2: Grupo de meninos tocando percussão no recreio Foto: Maristela Maciel, Agosto, 2015.

Uma das provocações realizadas em campo, para analisar a perspectiva do jovem foi à fotografia. Utilizar a fotografia como ferramenta do trabalho etnográfico. Propor que o próprio informante contribuísse com sua perspectiva tirando as fotografias a partir de seu ponto de vista. Estas fotos são usadas para acompanhar as notas registradas no diário de campo. Os alunos estão sendo fotografados e fotografando suas impressões sobre a escola. 

e-ISSN 2016/Atual: 2525-7870 | e-ISSN 2015/2016: 2447-018X

A escola pode ser vista como um espaço facilitador das sociabilidades juvenis possibilitando encontros e desencontros, este espaço público de reconhecimento social, pode possibilitar as aproximações com as culturas juvenis e suas expressões.

\section{Referências}

ABRAMO, Helena Wendel; BRANCO, Pedro Paulo Martoni. (Org.) Retratos da Juventude Brasileira: análises de uma pesquisa nacional. São Paulo: Instituto Cidadania/Fundação Perseu Abramo, 2005.

ARIÉS, Philippe. História Social da Criança e da Família. Rio de Janeiro, Editora LTC, 1981.

CALLIGARIS, Contardo. A Adolescência. São Paulo. Publifolha. 2000.

CIPINIUK, Tatiana Arnaud C. Etnografia em escola pública e seus desafios: um olhar sobre o método aplicado no itinerário do trabalho de campo. Disponível em: < Http://e-

revista.unioeste.br/index. php/educereeteducare/issue/view/591>Acesso em: 16/11/2014.

DAL'IGNA, Maria Cláudia. Família S/A: um estudo sobre a parceria família-escola. 2011,182p. Universidade Federal do Rio Grande do Sul. Faculdade de Educação. Programa de Pós-Graduação em Educação, (Tese doutorado). Disponível em:

$<$ http://www.michelfoucault.com.br/files/Maria\%20Claudia\%20Dal-Igna\%20-\%20tese\%20\%2017jun13.pdf> Acesso em: 26/04/2015.

DAUSTER, Tânia, TOSTA, Sandra P. e ROCHA, Gilmar. Etnografia e educação: culturas escolares, formação e sociabilidades infantis e juvenis. Rio de Janeiro: Lamparina, 2012.

FONSECA, Cláudia. Preparando-se para a vida: reflexões sobre escola e adolescência em grupos populares. Em Aberto. Ano 14, n.61, jan./mar. 1994. P.144-155. Disponível em: < http://www.emaberto.inep.gov.br/index. php/emaberto/article/viewFile/921/827> Acesso: 27/01/2015.

FONSECA, Cláudia. Quando cada caso NÃO é um caso. Pesquisa etnográfica e educação. Revista Brasileira de Educação, n. 10, jan./abr. 1999. Disponível em: < http://claudialwfonseca.webnode.com.br/publica\%C3\%A7\%C3\%B5es/antropologia-metodoetica/> Acesso: 14/10/2013.

GEERTZ, Clifford. A interpretação das culturas. Rio de Janeiro: LTC, 1989.

GOLDENBERG, Mirian. A arte de pesquisar: como fazer pesquisa qualitativa em Ciências Sociais. Rio de Janeiro: Record, 2009.

GROSSI, Esther Pillar (Org.). Como areia no alicerce: ciclos escolares. São Paulo: Paz e Terra, 2004.

GUSMÃO, Neusa Maria Mendes. Antropologia e educação: Origens de um diálogo. Caderno CEDE vol.18, no 43, dez 1997. Disponível em: < http://www.scielo.br/scielo.

php?script=sci_arttext\&pid=S0101-32621997000200002> Acesso: 14/10/2013. 
MEAD, Margaret. Adolescencia Sexo y Cultura em Samoa. Disponível em: < https://pt. scribd.com/doc/194272222/Margaret-Mead-Adolescencia-Sexo-y-Cultura-en-Samoa< Http://e-revista.unioeste.br/index.php/educereeteducare/issue/view/591>Acesso em: 16/05/2016.

PREFEITURA MUNICIPAL DE PORTO ALEGRE. Ciclos de Formação: proposta política pedagógica da escola cidadã. Porto Alegre, Cadernos Pedagógicos nº 9 /Abril de 1999.

PRO dia nascer feliz. Direção e Roteiro: João Jardim. Brasil. Copacabana filmes, 2005. DVD, drama, $87 \mathrm{~min}$., color, $35 \mathrm{~mm}$.

ROCHA, Ana Luiza Carvalho da. A Escola por ciclos, a dissolução da inteligência humana no mundo da natureza. In: ROCHA,A.L.C. GROSSI, Esther P. Como areia no alicerce : ciclos escolares, São Paulo: Paz e Terra, 2004, p. 111-135.

TOSTA, Sandra Pereira e CARVALHO, Andréa Pinheiro Tomaz. Dinâmicas culturais e educação: apropriação e (re) significação de espaços escolares por adolescentes. Linhas críticas, v. 21, n. 44 (2015) Disponível em:<

http://periodicos.unb.br/index.php/linhascriticas/issue/current/showToc.> Acesso em: 06/06/2015. 